\title{
WORKLOAD DAN PENGARUHNYA TERHADAP BURNOUT SERTA TURNOVER INTENTION KARYAWAN PERBANKAN
}

\author{
Tri Wulida Afrianty 1)*, Ni Nyoman Ari Astuti Dewi ${ }^{10}$ \\ 1) Fakultas Ilmu Administrasi, Universitas Brawijaya \\ *Penulis Korespondensi: twulidafia@ub.ac.id, ninyoman1246@gmail.com
}

\begin{abstract}
Abstrak
Beban kerja (workload) merupakan tuntutan terkait pekerjaan yang dibebankan kepada karyawan dalam jangka waktu tertentu. Beban kerja dapat menjadi stresor bagi karyawan yang bersangkutan serta memiliki kemungkinan untuk mempengaruhi sikap dan perilaku kerja karyawan. Terkait dengan hal ini, maka penelitian ini bertujuan untuk menganalisis pengaruh beban kerja (workload) terhadap burnout yang dirasakan oleh karyawan maupun niat berhentinya (turnover intention). Selain menganalisis pengaruh langsung, penelitian ini juga menguji peran burnout sebagai variabel mediasi dalam hubugan antara workload dan turnover intention karyawan. Terdapat empat hipotesis yang diuji dalam penelitian ini yang keseluruhannya menggambarkan keterkaitan antar variabel seperti yang diidentifikasi dalam tujuan penelitian. Seluruh hipotesis diuji dengan menggunakan pendekatan partial least square (PLS) dengan bantuan software SmartPLS versi 3. Keseluruhan sampel pada penelitian ini berjumlah 67 karyawan Micro Banking Cluster Bank Mandiri Area Balikpapan. Hasil penelitian ini menunjukan bahwa workload memiliki pengaruh positif dan signifikan terhadap burnout dan turnover intention, burnout memiliki pengaruh positif dan signifikan terhadap turnover intention, dan burnout memediasi pengaruh workload terhadap turnover intention.
\end{abstract}

Keywords: Beban Kerja (Workload), Niat Berhenti (Turnover Intention), Burnout

Article Information:

Received Date: 27 Oktober 2021

Revised Date: 7 November 2021

Accepted Date: 15 November 2021 


\section{PENDAHULUAN}

Pada era persaingan bisnis yang semakin ketat seperti saat ini, tidak terkecuali pada sektor perbankan, mempertahankan karyawan terbaik yang dimiliki oleh perusahaan merupakan sebuah tantangan yang besar terutama dengan adanya fenomena war of talent. Dengan kata lain, perusahaan, termasuk yang berada pada sektor perbankan, dihadapkan pada kebutuhan untuk memberikan perhatian yang serius terhadap upaya untuk mempertahankan sumber daya manusia unggul dan berkualitas yang dimilikinya agar mereka tidak keluar atau berpindah dari perusahaan. Perkembangan pesat industri perbankan yang salah satunya ditandai dengan munculnya berbagai inovasi produk yang ditawarkan oleh perbankan merupakan salah satu faktor pendorong meningkatnya persaingan antar pelaku bisnis yang berada pada sektor perbankan di Indonesia (Ramadhany, 2018). Untuk dapat tetap bertahan dalam persaingan yang tinggi dan agar tetap mempertahankan kepercayaan masyarakat, perusahaan cenderung melakukan peningkatan target-target dan perbaikan pada perusahaan. Karyawan akan dituntut untuk bekerja secara maksimal dan berkontribusi penuh agar keberhasilan dapat dicapai. Namun, tidak dapat dipungkiri bahwa tuntutan bekerja yang tinggi dengan melebihi kemampuan yang dimiliki oleh karyawan dapat memberikan tekanan dalam bekerja. Ziaei (2015) menyatakan bahwa "bekerja pada lingkungan yang penuh dengan tekanan dapat memberikan resiko kesehatan pada karyawan yang disebut sebagai burnout".

Istilah burnout pertama kali diperkenalkan oleh Freudenberg (1974) sebagai "rasa kelelahan yang diakibatkan dari permintaan energi, kekuatan, dan sumber daya yang berlebihan”. Pada akhir Mei 2019, World Health Organization (WHO) menyatakan bahwa burnout termasuk dalam klasifikasi penyakit yang memiliki keterkaitan dengan bekerja yang digambarkan sebagai sindrom yang disebabkan oleh stres di tempat kerja yang tidak dapat dikendalikan. Fenomena burnout yang terjadi pada seseorang dapat disebabkan oleh adanya beban kerja berlebihan yang dapat menguras energi dan kemampuan seseorang dalam melakukan tugasnya. Beban kerja (workload) yang tidak sesuai dengan keterampilan dan potensi karyawan serta dengan tingkat intensitas yang tinggi dapat menjadi salah satu faktor pendorong terjadinya burnout pada karyawan. Selain itu, beban kerja yang berlebihan juga dapat memicu karyawan untuk memiliki keinginan keluar dari perusahaan atau yang disebut sebagai turnover intention. Terdapat kemungkinan bahwa karyawan akan berpikir untuk meninggalkan pekerjaan mereka ketika merasa sangat terbebani.

PT. Bank Mandiri (Persero) Tbk merupakan salah satu BUMN yang bergerak dalam bidang perbankan di Indonesia. Kepercayaan yang diberikan oleh masyarakat Indonesia menjadikan Bank Mandiri sebagai salah satu pesaing kuat dalam dunia perbankan di Indonesia. Salah satu strategi yang menjadi fokus Bank Mandiri adalah meningkatkan efisiensi kinerja pada Micro Banking Cluster untuk menjadi pendorong utama pertumbuhan bisnis pada segmen mikro di Indonesia (Annual Report Bank Mandiri, 2020). Micro Banking Cluster merupakan unit kerja Bank Mandiri dalam melayani kredit yang diberikan kepada pelaku usaha mikro untuk membiayai kebutuhan usahanya. Menjadi salah satu fokus utama Bank Mandiri, tentu saja menyebabkan Micro Banking Cluster harus dapat mengelola sumber daya yang dimilikinya secara optimal, termasuk sumber daya manusianya (karyawan). Karyawan diharapkan dapat bekerja secara optimal sesuai dengan tugas yang diberikan oleh perusahaan. Micro Banking Cluster ini berfokus pada kegiatan kredit, yang tentu saja memiliki resiko tersendiri. Karyawan dituntut untuk bekerja dengan teliti dalam melakukan transaksi kredit terhadap nasabah dalam jangka waktu yang terbatas sesuai dengan tujuan yang ditetapkan oleh perusahaan. Bukan tidak mungkin hal ini dapat menciptakan tekanan bagi karyawan 
dalam melakukan pekerjaannya, bahkan dapat menimbulkan kelelahan dan stress kerja yang tinggi dan berkepanjangan sehingga menimbulkan burnout serta niat untuk berhenti dari pekerjaannya. Terkait dengan hal ini, penelitian ini dilakukan untuk menganalisis apakah terdapat pengaruh beban kerja (workload) yang dimiliki oleh karyawan Micro Banking Cluster Bank Mandiri Area Balikpapan terhadap burnout dan turnover intention mereka. Penelitian ini juga menganalisis kemungkinan peran mediasi burnout dalam pengaruh workload terhadap turnover intention karyawan Micro Banking Cluster Bank Mandiri Area Balikpapan. Lokasi penelitian ini dipilih dengan pertimbangan bahwa sebagaimana halnya dengan Micro Banking Cluster Bank Mandiri lainnya yang dituntut untuk meningkatkan efisiensi kerjanya oleh PT. Bank Mandiri agar dapat menjadi pendorong utama pertumbuhan bisnis pada segmen mikro di Indonesia (Annual Report Bank Mandiri, 2020), tentu saja hal ini menimbulkan tantangan tersendiri bagi karyawan Micro Banking Cluster Bank Mandiri Area Balikpapan. Tantangan tersebut diantaranya adalah adanya tuntutan untuk meningkatkan kinerja. Di sisi lain, tuntutan kinerja yang tinggi ini memiliki kemungkinan untuk menimbulkan stres kerja bahkan burnout bagi karyawannya. Oleh karena itulah maka penelitian ini berupaya untuk menganalisis kemungkinan penyebab terjadinya burnout (misalnya workload) beserta akibatnya (misalnya turnover intention).

\section{TINJAUAN PUSTAKA}

\section{Teori Job Demands-Resources/ JD-R}

Teori JD-R memiliki dua aspek yaitu job demands (tuntutan pekerjaan) dan job resources (sumber daya pekerjaan). Bakker dan Demerouti (2014) menjelaskan bahwa job demands (tuntutan pekerjaan) mengacu kepada aspek fisik, psikologis, sosial, dan organisasi yang membutuhkan upaya yang dapat mempengaruhi aspek fisik maupun psikologis individu. Di sisi lain, job resources mengacu kepada aspek fisik, psikologis, dan sosial dari pekerjaan yang berkontribusi pada pencapaian tujuan pekerjaan,, mengurangi job demands yang terkait dengan aktivitas fisiologis atau psikologis tertentu, serta mendorong pembelajaran dan pengembangan diri karyawan.

Adanya job demands yang berlebihan, kemungkinan besar akan memicu terjadinya stres pada karyawan. Ketika karyawan harus bekerja sangat keras untuk memenuhi tuntutan pekerjaannya, maka hal ini akan mengarah pada reaksi negatif seperti depresi, kecemasan, dan terjadinya burnout (kelelahan) (Schaufeli dan Bakker, 2004). Menurut Gann dalam Maslach dan Jackson (1981) "stressor di lingkungan pekerjaan disebabkan oleh workload yang penuh tekanan dari lingkungan kerja dan berkaitan erat dengan terjadinya burnout pada individu".

Pada sisi lain, job resources dapat berperan dalam proses motivasi karyawan. Hal ini berarati bahwa job resources pada lingkungan pekerjaan akan memberikan dampak yang positif bagi karyawan maupun organisasi terkait komitmen karyawan terhadap organisasi, intention to stay, perilaku peran, keselamatan karyawan, dan kinerja yang unggul (Schaufeli, 2017). Dalam penelitian ini, dengan menggunakan kerangka teori JD-R, maka workload yang merepresentasikan salah satu job demand diduga memiliki pengaruh terhadap menigkatnya burnout maupun turnover intention karyawan.

\section{Workload}

Beban kerja (workload) merupakan sebuah istilah yang dapat didefinisikan sebagai tuntutan yang dibebankan kepada karyawan terkait dengan pekerjaannya. Faulkner dan Patiar (1997) dan Lo dan Lamm (2005) mengamati bahwa beban kerja yang berlebihan dapat menjadi sumber stres di tempat kerja. Dengan kata lain beban kerja dapat diartikan sebagai jumlah pekerjaan yang diberikan kepada seseorang dalam jangka waktu tertentu 
serta dapat menjadi stresor bagi karyawan. Beban kerja dapat dilihat dari sisi kuantitatif maupun kualitatif. Beban kerja kuantitatif berkaitan dengan jumlah pekerjaan yang diterima oleh setiap karyawan dalam jangka waktu tertentu, sedangkan beban kerja kualitatif terkait dengan faktor psikologis karyawan yang ditimbulkan oleh pekerjaanya. Pengukuran workload dilakukan dengan menggunakan metode SWAT (Subjective Workload Assessment Technique) yang dikemukakan oleh Reid dan Nygren (1998) dengan yiga dimensi yaitu, beban waktu (time load), beban usaha mental (mental effort load) dan beban tekanan psikologi (psychological pressurelLoad).

\section{Burnout}

Pembahasan burnout pertama kali diterbitkan dalam artikel berjudul "Staff Burnout" yang dipublikasikan pada tahun 1974 pada Journal of Social Issues oleh Frendenbeurg. Menurut World Health Organization (WHO), "burnout atau kelelahan termasuk dalam klasifikasi penyakit akibat bekerja yang digambarkan sebagai sindrom yang disebabkan oleh pengelolaan stres di tempat kerja yang tidak dapat dikendalikan". Menurut Lubis (2016:58) "burnout adalah suatu kondisi yang ditandai dengan menurunnya produktivitas karena stress yang dialami di tempat kerja secara terus menerus". Berdasarkan definisi tersebut, burnout dapat difahami sebagai sindrom kelelahan secara emosional yang terjadi pada individu yang sangat mempengaruhi kinerjanya.

$$
\text { Maslach dan Jackson }
$$

mengidentifikasi bahwa terdapat tiga dimensi dalam burnout, yaitu kelelahan emosional (emotional exhaustion), depersonalisasi (depersonalization), dan penghargaan diri (personal accomplishment).

\section{Turnover Intention}

Turnover intention dapat diartikan sebagai keinginan sadar karyawan untuk berhenti bekerja atau meninggalkan organisasi tempat mereka bekerja (Çelik dan Çira, 2013). Turnover intention dapat ditunjukkan dari adanya keinginan karyawan untuk meninggalkan pekerjaan dan mencari pekerjaan baru dengan sengaja (Avci dan Küçïkusta, 2009).

Cotton dan Tuttle

mengklasifikasikan faktor-faktor yang mempengaruhi turnover intention menjadi tiga kelompok:

1) Faktor lingkungan yang meliputi tingkat pengangguran nasional dan sektoral, persepsi terhadap pekerjaan dan kehadiran serikat pekerja, serta tingkat partisipasi angkatan kerja kandidat baru;

2) Faktor terkait pekerjaan seperti upah, kinerja, kejelasan peran, pengulangan pekerjaan, kepuasan terhadap upah, peluang promosi dan komitmen organisasi;

3) Karakteristik pribadi seperti usia, pengalaman, jenis kelamin, tingkat pendidikan, status perkawinan, kemampuan, dan kecenderungan perilaku.

Turnover intention dapat menyebabkan kerugian yang signifikan bagi perusahaan jika perusahaan tersebut tidak mengidentifikasi dan mengambil tindakan untuk mencegahnya (Sahin, 2011). Turnover intention yang tinggi ditunjukkan dengan meningkatnya frekuensi karyawan yang ingin berhenti dari pekerjaan mereka dan berpotensi meningkatkan kerugian finansial dan akibat negatif lainnya (Demir and Tütüncü, 2010).

Newman, et al. (2011) mengukur turnover intention dengan menggunakan beberapa indikator yang diantaranya meliputi: keinginan untuk keluar dari pekerjaan, keinginan mencari pekerjaan di tempat kerja yang lain, keinginan untuk berpindah ke perusahaan lain dalam 6 bulan ke depan, dan keinginan untuk mencari informasi pekerjaan lain.

\section{Hipotesis Penelitian}

Dengan menggunakan kerangka teori Job Demands-Resources, dalam penelitian kami menduga bahwa workload yang berperan 
sebagai job demand memiliki pengaruh terhadap menigkatnya burnout maupun turnover intention karyawan. Sehingga hipotesis yang kami susun adalah:

H1: Workload (X) memiliki pengaruh signifikan terhadap Turnover Intention (Y).

$\mathrm{H}$ 2: Workload (X) memiliki pengaruh signifikan terhadap Burnout (Z).

H3: Burnout (Z) memiliki pengaruh signifikan terhadap Turnover Intention (Y).

H4: Workload (X) memiliki pengaruh signifikan terhadap Turnover Intention (Y) melalui Burnout (Z).

Adapun model hipotesis ini digambarkan seperti pada gambar 1 .

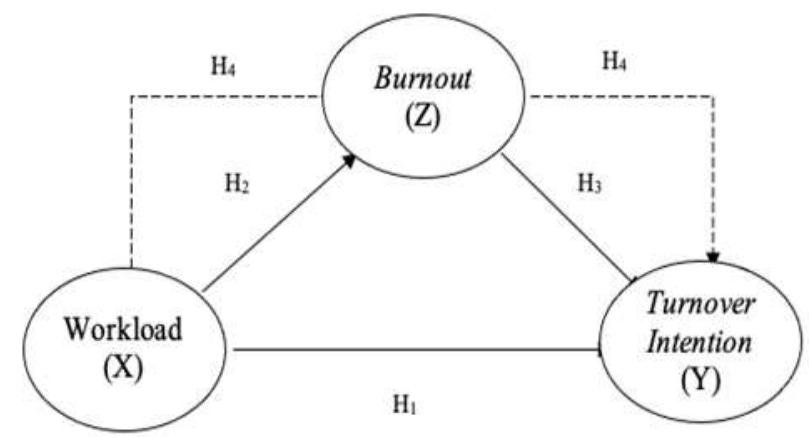

Gambar 1. Kerangka Penelitian

\section{METODE PENELITIAN}

Penelitian ini menggunakan pendekatan kuantitatif. Lokasi penelitian ini adalah pada Micro Banking Cluster Bank Mandiri Area Balikpapan yang terletak di Jl.Jend Sudirman No.71 Klandasan Ilir, Balikpapan Kota, Kota Balikpapan, Kalimantan Timur. Sejumlah 67 karyawan tetap Micro Banking Cluster Bank Mandiri Area Balikpapan dijadikan sebagai sampel penelitian. Pengumpulan data dilakukan dengan metode survei menggunakan kuesioner. Data yang diperoleh kemudian dianalisis dengan pendektan PLS (Partial Least Square).

\section{HASIL DAN PEMBAHASAN}

\section{Distribusi Frekuensi Variabel Penelitian}

Variabel Workload (X)

Dari hasil perhitungan statistik deskriptif, diketahui bahwa grand mean dari variabel workload adalah 3,82. Hal ini menunjukan bahwa tingkat workload pada karyawan Micro Banking Cluster Bank Mandiri Area Balikpapan dapat dikategorikan tinggi. Item penilaian tertinggi adalah "Pekerjaan yang saya lakukan memiliki tingkat resiko yang tinggi" dengan rata-rata 4,22 dan item penilaian terendah adalah "Saya sering kali mendapatkan gangguan selama melakukan pekerjaan" dengan rata-rata 3,36.

\section{Variabel Burnout (Z)}

Dari hasil perhitungan statistik deskriptif, diketahui bahwa grand mean variabel burnout adalah 2,65. Hal ini menunjukan bahwa tingkat burnout pada karyawan Micro Banking Cluster Bank Mandiri Area Balikpapan ini termasuk dalam kategori sedang. Item penilaian tertinggi adalah "Saya selalu merasa lelah pada akhir jam kerja" dengan rata-rata 4,03, sedangkan item penilaian terendah adalah "Saya merasa terkadang rekan kerja menyalahkan saya atas beberapa masalah mereka" dan "Saya telah mencapai banyak hal berharga dari pekerjaan ini” dengan rata-rata 1,82 .

\section{Variabel Turnover Intention (Y)}

Dari hasil perhitungan statistik deskriptif, diketahui bahwa grand mean variabel turnover intention adalah 2,61. Hal ini menunjukan bahwa tingkat turnover intention pada karyawan Micro Banking Cluster Bank Mandiri Area Balikpapan ini termasuk dalam kategori sedang. Item penilaian tertinggi adalah "Saya merasa bekerja selain diperusahaan ini akan lebih menyenangkan" dengan rata-rata 3,43 dan item penilaian terendah adalah "Saya merasa sudah tidak mempunyai motivasi untuk tetap bekerja di perusahaan ini" dengan rata-rata 2,00. 
Analisis Data dengan Pendekatan PLS (Partial Least Square)

Evaluasi Model Pengukuran (Outer Model)

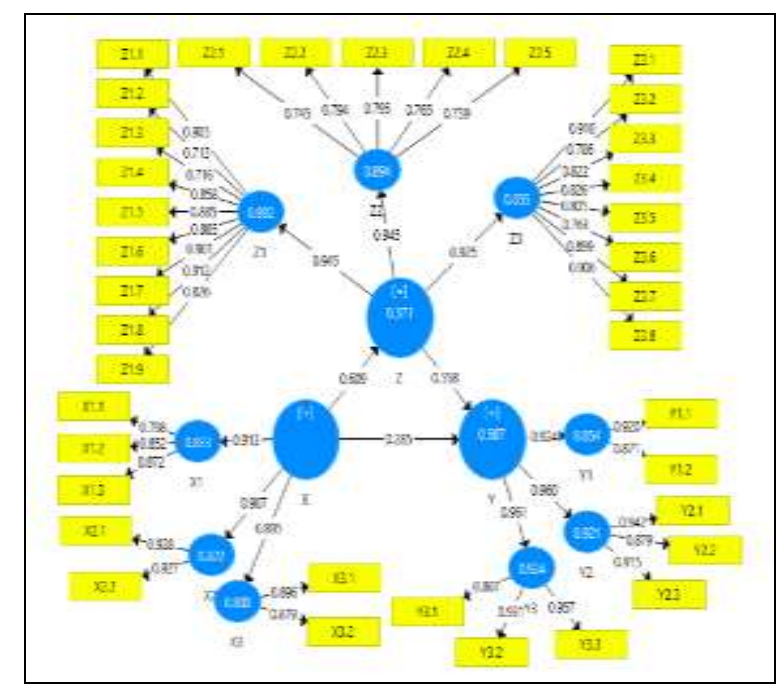

Gambar 2. Model Pengukuran (Outer Model)

Teknik analisis data dengan SmartPLS menggunakan 3 kriteria yaitu Convergent Validity, Discriminant Validity, dan Composite Reliability.

\section{Validitas Konvergen (Convergent Validity)}

Hasil pengujian nilai faktor loading di atas 0,7 dapat dikatakan ideal dan valid. Nilai yang digunakan pada penelitian ini adalah 0,7. Tabel 1 berikut adalah tabel outer loadings untuk mengukur nilai faktor loading pada penelitian ini.
Tabel 1. Outer Loadings

\begin{tabular}{|c|c|c|c|c|}
\hline & $\begin{array}{c}\text { Original } \\
\text { Sample }(0)\end{array}$ & $\begin{array}{l}\text { Standard } \\
\text { Deviation } \\
\text { (STDEV) }\end{array}$ & $\begin{array}{l}\text { T Statistics } \\
(|\mathrm{O} / \mathrm{STDEV}|)\end{array}$ & P Values \\
\hline $\mathrm{X} 1.1<-\mathrm{X} 1$ & 0.798 & 0.053 & 14.936 & 0.000 \\
\hline $\mathrm{X} 1.2<-\mathrm{X} 1$ & 0.852 & 0.031 & 27.101 & 0.000 \\
\hline $\mathrm{X} 1.3<-\mathrm{X} 1$ & 0.872 & 0.037 & 23.850 & 0.000 \\
\hline $\mathrm{X} 2.1<-\mathrm{X} 2$ & 0.928 & 0.020 & 47.432 & 0.000 \\
\hline $\mathrm{X} 2.2<-\mathrm{X} 2$ & 0.927 & 0.020 & 46.024 & 0.000 \\
\hline $\mathrm{X} 3.1<-\mathrm{X} 3$ & 0.896 & 0.021 & 43.492 & 0.000 \\
\hline $\mathrm{X} 3.2<-\mathrm{X} 3$ & 0.879 & 0.018 & 49.870 & 0.000 \\
\hline $\mathrm{Y} 1.1<-\mathrm{Y} 1$ & 0.920 & 0.010 & 88.806 & 0.000 \\
\hline $\mathrm{Y} 1.2<-\mathrm{Y} 1$ & 0.871 & 0.039 & 22.339 & 0.000 \\
\hline $\mathrm{Y} 2.1<-\mathrm{Y} 2$ & 0.942 & 0.014 & 67.420 & 0.000 \\
\hline$Y 2.2<-Y 2$ & 0.879 & 0.031 & 28.637 & 0.000 \\
\hline$Y 2.3<-Y 2$ & 0.915 & 0.017 & 53.468 & 0.000 \\
\hline $\mathrm{Y} 3.1<-\mathrm{Y} 3$ & 0.867 & 0.034 & 25.787 & 0.000 \\
\hline $\mathrm{Y} 3.2<-\mathrm{Y} 3$ & 0.931 & 0.013 & 69.329 & 0.000 \\
\hline$Y 3.3<-Y 3$ & 0.957 & 0.008 & 117.053 & 0.000 \\
\hline $\mathrm{Z} 1.1<-\mathrm{Z} 1$ & 0.905 & 0.020 & 46.159 & 0.000 \\
\hline $\mathrm{Z} 1.2<-\mathrm{Z} 1$ & 0.713 & 0.055 & 13.062 & 0.000 \\
\hline $\mathrm{Z} 1.3<-\mathrm{Z} 1$ & 0.716 & 0.056 & 12.867 & 0.000 \\
\hline $\mathrm{Z} 1.4<-\mathrm{Z} 1$ & 0.858 & 0.028 & 31.143 & 0.000 \\
\hline $\mathrm{Z} 1.5<-\mathrm{Z} 1$ & 0.885 & 0.026 & 34.475 & 0.000 \\
\hline $\mathrm{Z} 1.6<-\mathrm{Z1}$ & 0.885 & 0.026 & 33.505 & 0.000 \\
\hline $\mathrm{Z} 1.7<-\mathrm{Z1}$ & 0.901 & 0.025 & 36.592 & 0.000 \\
\hline $\mathrm{Z} 1.8<-\mathrm{Z1}$ & 0.912 & 0.020 & 44.800 & 0.000 \\
\hline$Z 1.9<-\mathrm{Z} 1$ & 0.826 & 0.049 & 16.965 & 0.000 \\
\hline $\mathrm{Z} 2.1<-\mathrm{Z2}$ & 0.745 & 0.075 & 9.898 & 0.000 \\
\hline $\mathrm{Z} 2.2<-\mathrm{Z2}$ & 0.794 & 0.052 & 15.310 & 0.000 \\
\hline $\mathrm{Z} 2.3<-\mathrm{Z} 2$ & 0.795 & 0.052 & 15.210 & 0.000 \\
\hline $\mathrm{Z} 2.4<-\mathrm{Z2}$ & 0.765 & 0.049 & 15.500 & 0.000 \\
\hline $\mathrm{Z} 2.5<-\mathrm{Z2}$ & 0.739 & 0.073 & 10.121 & 0.000 \\
\hline $\mathrm{Z} 3.1<-\mathrm{Z} 3$ & 0.910 & 0.018 & 51.821 & 0.000 \\
\hline $\mathrm{Z} 3.2<-\mathrm{Z3}$ & 0.786 & 0.051 & 15.331 & 0.000 \\
\hline $\mathrm{Z} 3.3<-\mathrm{Z} 3$ & 0.822 & 0.042 & 19.576 & 0.000 \\
\hline $\mathrm{Z} 3.4<-\mathrm{Z} 3$ & 0.826 & 0.036 & 23.160 & 0.000 \\
\hline $\mathrm{Z} 3.5<-\mathrm{Z3}$ & 0.805 & 0.038 & 21.118 & 0.000 \\
\hline $\mathrm{Z} 3.6<-\mathrm{Z} 3$ & 0.763 & 0.081 & 9.383 & 0.000 \\
\hline$Z 3.7<-Z 3$ & 0.899 & 0.020 & 44.151 & 0.000 \\
\hline $\mathrm{Z3} .8<-\mathrm{Z3}$ & 0.906 & 0.019 & 47.442 & 0.000 \\
\hline
\end{tabular}

Sumber: Data primer diolah, 2021

Validitas Diskriminan (Discriminant Validity) Discriminant validity dinilai berdasarkan pengukuran nilai cross loading dengan konstruk. Model discriminant validity yang baik adalah jika nilai loading setiap indikator pada variabel laten memiliki nilai loading yang paling besar dibandingkan dengan nilai loading variabel laten lainnya. Tabel 2 berikut menyajikan hasil pengujian discriminant validity pada penelitian ini. 
Tabel 2. Nilai Cross Loading

Tabel 3. Goodness of Fit

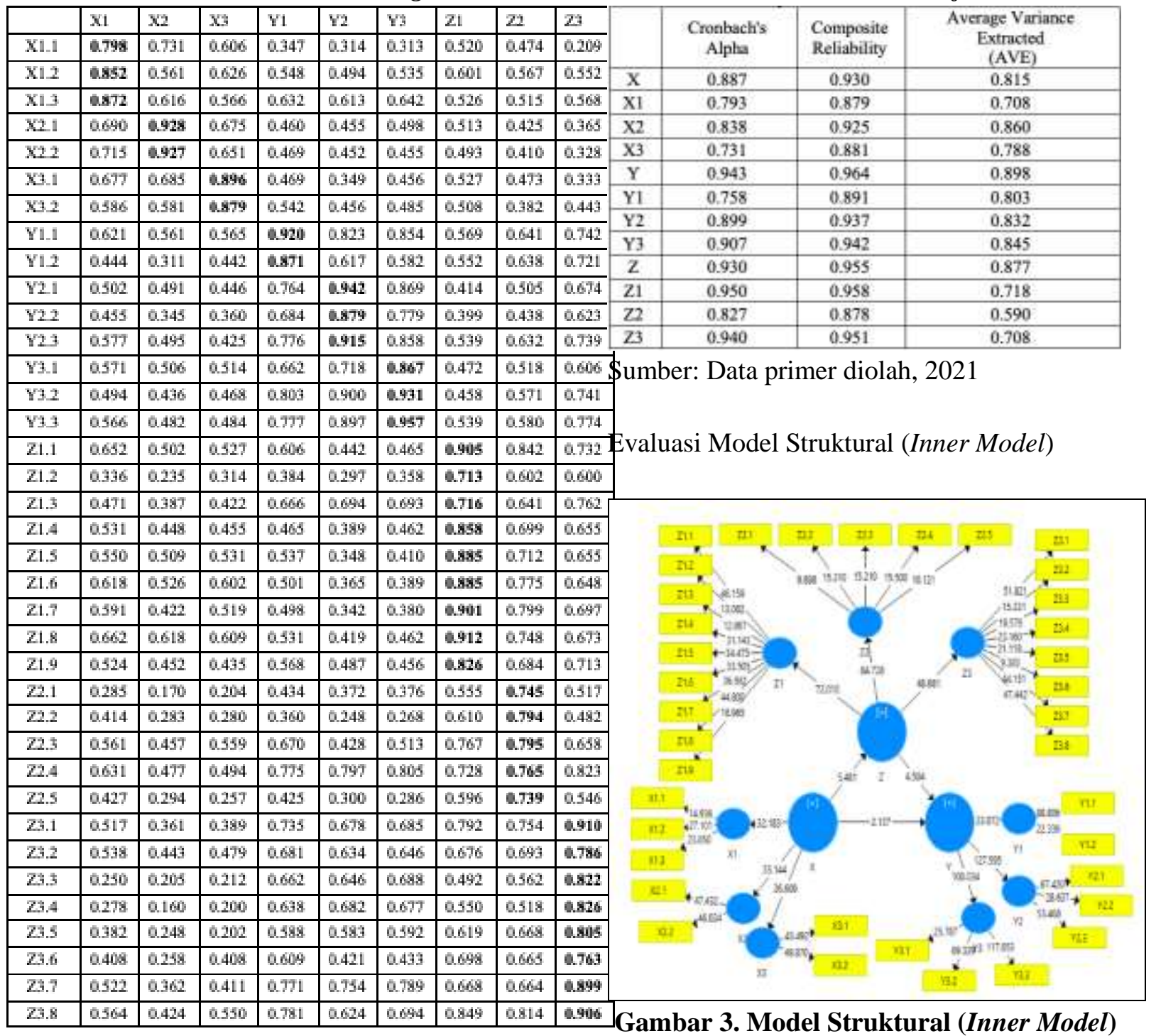

Sumber: data primer diolah, 2021

Evaluasi Model

Evaluasi model pengukuran dengan square root of average variance extracted (AVE) membandingkan nilai akar AVE dengan korelasi antar konstruk. Jika nilai akar AVE lebih tinggi daripada nilai korelasi di antara konstruk, maka discriminant validity yang baik tercapai. Nilai AVE yang lebih besar dari 0,5 juga direkomendasikan. Pengujian selanjutnya untuk menganalisis outer model adalah melihat reliabilitas konstruk variabel laten yang diukur dengan 2 kriteria yaitu composite reliability dan Cronbach Alpha dan dinyatakan reliabel jika nilai keduanya diatas 0,70 .
Model struktural dievaluasi dengan menggunakan R-square untuk konstruk dependen uji t serta signifikansi dari koefisien parameter jalur struktural.

$\underline{\text { Koefisien Determinasi (R2) }}$

Tabel 4. Nilai R-Square

\begin{tabular}{|c|c|}
\hline Variabel & R Square \\
\hline $\mathbf{Z}$ & 0.371 \\
\hline $\mathbf{Y}$ & 0.587 \\
\hline
\end{tabular}

Sumber: Data primer diolah, 2021

Tabel diatas menunjukan nilai R-Square untuk variabel turnover intention diperoleh sebesar 0,371, hal ini menunjukan bahwa $37,1 \%$ 
variabel burnout dapat dipengaruhi oleh variabel workload.

Nilai R-Square turnover intention sebesar 0,587 menunjukan bahwa variable turnover intention dipengaruhi oleh variabel workload dan burnout sebesar 58,7\%.

Predictive relevance (Q2)

Perhitungan predictive relevance pada penelitian ini adalah sebagai berikut

Nilai Q2 $=1-(1-\mathrm{R} 2) \times(1-\mathrm{R} 2)$

Nilai Q2 $=1-(1-0,371) \times(1-0,587)$

$=0,7402$

Dari hasil perhitungan terlihat bahwa nilai Q2 sebesar 0,7402. Hal ini menunjukan bahwa keragaman data penelitian dapat dijelaskan oleh model struktural yang dirancang adalah sebesar 75,02\%.

\section{Pengujian Hipotesis}

Hipotesis 1

Pengujian pengaruh variabel workload terhadap variabel turnover intention didapatkan koefisien jalur sebesar 0,285 dengan t hitung sebesar 2,137. Hubungan yang positif menjelaskan bahwa semakin meningkatnya workload maka turnover intention akan semakin tinggi. Karena nilai pada $t$ hitung lebih besar dari $t$ tabel $(1,960)$ atau $\mathrm{p}(0,033) \leq 0,05$, dapat dijelaskan bahwa hipotesis 1 diterima yang berarti bahwa workload memiliki pengaruh positif dan signifikan terhadap turnover intention. Hasil penelitian ini sejalan dengan beberapa hasil penelitian terdahulu yang diantaranya adalah penelitian yang dilakukan Qureshi (2013) dan Putra (2016) yang menemukan adanya pengaruh yang positif dan signifikan dari workload terhadap turnover intention.

\section{Hipotesis 2}

Pengujian hipotesis variabel workload terhadap variabel burnout didapatkan koefisien jalur sebesar 0,609 dan t hitung sebesar 5,482. Arah hubungan yang positif dapat ditunjukan dengan nilai $\mathrm{t}$ hitung yang lebih besar dari $\mathrm{t}$ tabel $(1,960)$ atau $p(0,000) \leq 0,05$. Hal ini menunjukkan bahwa hipotesis 2 diterima yang berarti bahwa dalam penelitian ini workload mempunyai pengaruh positif dan signifikan terhadap burnout. Hasil penelitian ini didukung oleh penelitian yang dilakukan oleh Xiaoming (2014) dan Atmaja (2019) yang mengidentifikasi adanya pengaruh yang positif dan signifikan dari workload terhadap burnout pada karyawan.

\section{Hipotesis 3}

Hasil pengujian pengaruh variabel burnout terhadap variabel turnover intention mendapatkan koefisien jalur sebesar 0,558 dengan thitung sebesar 4,504. Nilai t hitung yang lebih besar dari $t$ tabel (1960) atau $p$ $(0,000) \leq 0,05$ menunjukkan bahwa hipotesis 3 penelitian ini ditrerima. Hal ini menjelaskan bahwa workload mempunyai pengaruh positif dan signfikan terhadap turnover intention. Hasil penelitian ini sejalan dengan hasil penelitian yang dilakukan oleh Xiaoming (2014) dan Ahmad (2016) yang menunjukkan bahwa terdapat pengaruh positif dan signifikan dari burnout terhadap turnover intention.

\section{Hipotesis 4}

Berdasarkan hasil perhitungan, besarnya pengaruh burnout sebagai variabel intervening adalah sebagai berikut :

$\mathrm{Y}=\mathrm{PYX}+(\mathrm{PYX} \times \mathrm{PYZ})$

Direct effect workload terhadap burnout sebesar 0,285

Indirect Effect $(\mathrm{IE})=\mathrm{PZX} \times \mathrm{PYZ}$

$=0,604 \times 0,558$

$=0,340$

Total Effect $(\mathrm{TE}) \quad=\mathrm{PYX}+(\mathrm{PZX} \times \mathrm{PYZ})$

$=0,286+0,340$

$=0,625$

Perhitungan pengaruh tidak langsung, dan total pengaruh hubungan antar variabel disajikan dalam sebuah ringkasan hasil, sebagai berikut: 
Tabel 5. Perhitungan Pengaruh Tidak Langsung

\begin{tabular}{|c|c|c|c|c|c|c|c|c|}
\hline \multirow{2}{*}{ Vurabel } & \multicolumn{2}{|c|}{$\begin{array}{l}\text { Koctisien } \\
\text { Languar }\end{array}$} & \multicolumn{2}{|c|}{$\begin{array}{l}\text { standat } \\
\text { error }\end{array}$} & \multirow{2}{*}{$\begin{array}{l}\text { Koeflicien } \\
\text { Tidak } \\
\text { Lungerng }\end{array}$} & \multirow{2}{*}{$\begin{array}{l}\text { s.t } \\
\text { Soltel }\end{array}$} & \multirow{2}{*}{ Hitueng } & \multirow{2}{*}{ Vulue $_{\text {vat }}^{p}$} \\
\hline & $x \rightarrow z$ & $Z \rightarrow Y$ & $x \rightarrow z$ & $x \rightarrow y$ & & & & \\
\hline$X \rightarrow Z \rightarrow Y$ & 0.609 & 0.558 & 0.111 & 0.124 & 0.340 & 0.098 & 3.478 & 0.001 \\
\hline
\end{tabular}

Sumber: Data primer diolah, 2021

Tabel 5 menjelaskan hasil dari pengujian hipotesis 4 yang menunjukan hubungan antara variabel workload dengan turnover intention melalui burnout menujukan nilai koefisien jalur tidak langsung sebesar 0,340 dengan nilai $\mathrm{t}$ statistik 3,478. Nilai $\mathrm{t}$ hitung yang menunjukan lebih besar dari $\mathrm{t}$ tabel $(1,960)$ atau $\mathrm{p}(0,001) \leq 0,05$ menjelaskan bahwa burnout mempeharuhi secara signifikan dalam menjembatani workload terhadap turnover intention. Hasil ini berarti bahwa hipotesis 4 penelitian ini diterima. Hasil penelitian ini sejalan dengan penelitian yang dilakukan oleh Leither dan Meechan (1986) dalam Jung (2012) yang mengungkapkan bahwa karyawan yang mengalami gangguan emosional akibat dari kelelahan yang dialami di tempat kerja serta adanya peningkatan beban kerja akan mengarah kepada turnover intention. Terjadinya burnout yang dialami oleh karyawan secara tidak langsung dapat dipicu dari adanya beban kerja secara berlebihan dan dapat menimbulkan turnover intention pada karyawan.

\section{KESIMPULAN DAN SARAN}

Hasil penelitian ini menunjukkan bahwa workload yang tinggi yang merupakan salah satu bentuk job demand memiliki pengaruh yang kuat terhadap munculnya burnout maupun keinginan dari karyawan tersebut untuk keluar dari pekerjaannya (turnover intention). Selain menggunakan perspektif teori Job Demands-Resources, mekanisme hubungan antar ketiga variabel penelitian ini juga dapat dijelaskan dengan menggunakan teori Stimulus Organism Response yang mana dalam penelitian ini workload merupakan stimulus yang berasal dari organisasi tempat karyawan bekerja yang kemudian stimulus tersebut mempengaruhi rasa dan fikiran individu yang bersangkutan (organism) yang pada akhirnya direspon dalam bentuk keinginan untuk keluar dari organisasi.

Dengan terbuktinya bahwa workload memiliki pengaruh yang signifikan terhadap burnout maupun turnover intention karyawan pada penelitian ini, maka perusahaan perlu untuk meninjau kembali beban kerja yang diberikan kepada karyawannya untuk memastikan bahwa beban kerja tersebut tidak melebihi kapasitas karyawannya. Hal ini penting dilakukan sebagai tindakan preventif bagi timbulnya dampak-dampak negatif, baik bagi karyawan maupun perusahaan seperti meningkatnya burnout dan turnover intention. Disamping melakukan analisis beban kerja, perusahaan perlu untuk mengupayakan berbagai bentuk dukungan terhadap karyawan sebagai bentuk "job resources" dari perspektif job demands-resources theory. Dukungan tersebut misalnya dapat berupa pemenuhan fasilitas kerja yang memadai, pemberian program pelatihan dan pengembangan karyawan yang dapat menigkatkan kapasitas karyawan dalam menyelesaikan pekerjaanya maupun mengimplementasikan bentuk job sharing yang dapat meringankan beban kerja karyawan.

\section{REFERENSI}

Ahmad, A., dan S. Afgan. 2016. The relationship of job stress and turnover intention in commercial banks of Pakistan by assessing the mediating role of burnout. Journal of Business Strategies, 10(1): 1 .

Annual Report PT.Bank Mandiri (Persero) Tbk. 2020.

https://bankmandiri.co.id/documents/3 $\underline{8265486 / 0 / \mathrm{AR}+2020+\% 23+\mathrm{PT}+\mathrm{Bank}}$ + Mandiri+\%28Persero\%29+Tbk+\%2 8IND\%29+23042021+LR.pdf/340ba6 c4-7bfd-6fd8-dd75-2412d0c3846f.

Diakses pada 2 Mei 2021

Atmaja, I. G. I. W., dan I. W. Suana. 2019. Pengaruh workload terhadap burnout 
dengan role stress sebagai variabel mediasi pada karyawan Rumours Restaurant. E-Jurnal Manajemen, 8(2): 815-844.

Bakker, A.B.,\& Demerouti, E. (2014). Job Demands-Resources Theory. In P.Y Chen \& C.L Cooper (Eds.) Work and Wellbeing: A Complete Reference Guide, Voll III. New York, USA: John Wiley \& Sons,Ltd

Faulkner, B. and Patiar, A. (1997), "Workplace induced stress among operational staff in the hotel industry", International Journal of Hospitality Management, Vol. 16 No. 1, pp. 99117

Freudenberg, Herbert. J. 1974. Staff Burnout. Journal of Social Issues. 30(1).159165.

Harnoto. 2002. Manajemen Sumber Daya Manusia. Jakarta: Prehallindo

Jung, H.S., Yoon, H.H., dan Kim, Y.J. 2012. Effects of Culinary Employees' Role Stress on Burnout and Turnover Intention in Hotel Industry: Moderating Effects on Employees' Tenure. The Service Industries Journal, 32(13). 2145-2165

Lo, K. and Lamm, F. (2005), "Occupational stress in the hospitality industry - an employment relations perspective", New Zealand Journal of Employment Relations, Vol. 30 No. 1, p. 23.

Lubis, Namora L. 2009. Depresi : Tinjauan Psikologis. Edisi Pertama. Jakarta: Kencana.

Maslach, C., dan S. E. Jackson. 1981. The measurement of experienced burnout. Journal of Organizational Behavior, 2(2): 99-113.

Qureshi, M. I., M. Iftikhar, S. G. Abbas, U. Hassan, K. Khan, dan K. Zaman. 2013. Relationship between job stress, workload, environment and employees turnover intentions: What we know, what should we know. World Applied Sciences Journal, 23(6): 764-770.

Reid, G. B., \& Nygren, T. E. (1988). The Subjective Workload Assessment Technique: A Scaling Procedure For Measuring Mental Workload. In N. Meshkati, \& P. A. Hancock (Eds).
Elsevier Science Publishers. Human Mental Workload. 185-218.

Rivai, V. 2009. Manajemen Sumber Daya Manusia untuk Perusahaan: Dari Teori Ke Teori. RajaGrafindo Persada. Jakarta.

Schaufeli, Wilmar.B. 2017. Applying the Job Demands-Resources model: A 'how to' guide to measuring and tackling work engagment and burnout. Organizational Dynamics.

Schaufeli, W.B.,\& Bakker, A.B. 2004. Job demands, job resources, and their relationship with burnout and engagement: : a multi sample stud. Journal Organization Behaviour : 25, 293-315.

Simamora, Henry. 2004.Manajemen Sumber Daya Manusia.Edisi Ketiga. Cetakan Pertama. Yogyakarta:STIE YKPN.

Tarwaka. 2004. Ergonomi Industri. Surakarta: UNIBA Press.

Wirawan. 2015. Manajemen Sumber Daya Manusia. In. Jakarta: RajaGrafindo Persada.

World Healt Organization (WHO). 2019. "Burnout an Occupational Phenomenon": International of Diseases. https://www.who.int/mental_health/ev idence/burn-out/en/. Diakses pada tanggal 7 Desember 2019.

Xiaoming, Y., B.-J. Ma, C. L. Chang, dan C.J. Shieh. 2014. Effects of workload on burnout and turnover intention of medical staff: A study. Studies on Ethno-Medicine, 8(3): 229-237.

Ziaei, M., Hamed Yarmohammad, Meisam Moradi, \&Mohammad Khandan. 2015. Level of Workload and Its Relationship with Job Burnout Among Administrative Staff. International Journal of Occupational Hygiene.6(3):53-60. 